\title{
ANÁLISE DA SUSCETIBILIDADE A \\ ESCORREGAMENTOS NOS ENTORNOS DOS \\ POLIDUTOS DE CUBATÃO-SP, ATRAVÉS DE \\ TÉCNICAS DE INFORMAÇÃO GEOGRÁFICA
}

\section{LANDSLIDES SUSCEPTIBILITY ANALYSIS IN THE NEIGHBORHOODS OF CUBATÃO (SÃO PAULO STATE, BRAZIL) PIPELINES, THROUGH GIS TECHNIQUES}

\section{Carvalho, C.M. ${ }^{1}$; Riedel, P.S. ${ }^{2}$}

${ }^{1}$ Geóloga, pela Universidade Estadual Paulista, UNESPcmcarv@hotmail.com

${ }^{2}$ Geóloga e Profa. Dra. do Departamento de Geologia Aplicada Instituto de Geociências e Ciências Exatas - Universidade Estadual Paulista, UNESP, Av. 24-A, 1515, Rio Claro - SP

\section{RESUMO}

Este trabalho utilizou técnicas de Sistemas de Informação Geográfica (SIGs), mais especificamente o modelo AHP (Analytical Hierarchy Process), para avaliar a suscetibilidade aos movimentos de massa nos entornos dos polidutos de Cubatão (SP).

Neste trecho da Serra do Mar, os principais movimentos de massa são os escorregamentos translacionais, devido às características geológicas e geomorfológicas presentes, aliadas à degradação da vegetação e à alta pluviosidade. Aspectos geológicos, geomorfológicos e de vegetação foram obtidos para a área de estudo, através de mapeamentos existentes, caracterizando os principais condicionantes do processo a ser analisado. Foram elaborados os mapas temáticos correspondentes aos condicionantes, que foram integrados em ambiente SIG, através do modelo AHP, que realiza uma soma ponderada dos condicionantes citados acima, atribuindose a eles pesos maiores ou menores, dependendo de sua influência na deflagração do processo em questão. O produto final foi uma Carta de Suscetibilidade aos Escorregamentos Translacionais, nos entornos dos polidutos de Cubatão, que possibilitou a análise da adequação dos métodos empregados, bem como da utilidade do mapa obtido na avaliação de áreas 
mais críticas nos dutos existentes e no planejamento de futuras malhas dutoviárias.

Palavras-chave: movimentos de massa, Análise Hierárquica Ponderada, meio-físico, Sistemas de Informação Geográfica

\begin{abstract}
GIS Analytical Hierarchy Process (AHP) was applied to evaluate landslide susceptibility along petroleum and gas pipelines in Cubatão (SP). In this area, the main landslides are related to the translation type, caused by geologic and geomorphologic conditions, associated with the degraded vegetation and high pluviosity. Geologic, geomorphologic and vegetation conditions were obtained from the study area to characterize the main geologic process features. Thematic maps related to these features were integrated through AHP model, which consider a weighted score, where each map must be associated with a list of scores, one per map class, depending on their influence in the process under consideration. The final product was a susceptibility map, which enabled an adequate analysis of this type of process as well as the evaluation of the critical areas along the existing pipelines and the future planning of new pipelines.
\end{abstract}

Key words: mass movements, Analytical Hierarchy Process, physicalenvironment, Geographical Information Systems (GIS).

\title{
1 - INTRODUÇÃO
}

O município de Cubatão, importante pólo industrial, localizado na Serra do Mar Paulista, tem sido alvo, há muitos anos, de processos naturais que envolvem principalmente movimentos de massa.As causas destes movimentos são as condições geomorfológicas adversas, aliadas à alta pluviosidade e à degradação da vegetação pela ação dos poluentes oriundos das atividades industriais. A perda da cobertura vegetal devido à ação dos poluentes atmosféricos, associada à chuva, ao tipo de rocha ou solo alterados e às altas declividades existentes na serra, condicionam uma predisposição a processos erosivos, causados por fatores que geram instabilidade no solo ou rocha, levando à movimentação destes para baixo, devido à ação da gravidade, caracterizando os movimentos de massa. $\mathrm{Na}$ área de estudo, os tipos de movimento de massa mais comuns são o escorregamento translacional e a corrida de massa. Neste trabalho foram abordados somente os escorregamentos translacionais. 
Existem na área inúmeros dutos, que transportam desde esgoto até gás natural e há a previsão de aumento desta malha dutoviária, ocasionado pela importante descoberta de gás natural na Bacia de Santos. Os últimos acidentes com vazamentos em dutos geraram um grande interesse por programas que envolvem sua integridade $\mathrm{e}$ confiabilidade $\mathrm{e}$, conseqüentemente, por estudos do meio físico que venham a contribuir com o aumento da segurança .

Os Sistemas de Informação Geográfica têm grande potencial de aplicação em estudos integrados do meio físico, seja na abordagem conhecida como "knowlegde driven"(baseada no conhecimento), seja através da abordagem "data driven" ( baseada em dados ). Neste trabalho, foi utilizada a abordagem "knowledge driven", onde o conhecimento sobre os processos que se desenvolvem, no tocante a seus condicionantes, é utilizado, de forma a conduzir o cruzamento dos dados. Esta abordagem permitiu que cada variável envolvida no processo fosse ponderada, de forma a refletir a sua importância relativa na problemática sob análise, para gerar uma carta de suscetibilidade aos escorregamentos translacionais da área de estudo, visando conhecer o comportamento do meio físico, nos entornos dos polidutos de Cubatão, no tocante ao tipo de escorregamento analisado.

\section{2 - OBJETIVOS E JUSTIFICATIVA}

Este trabalho tem como objetivo gerar uma carta de suscetibilidade aos escorregamentos translacionais nos entornos dos polidutos de Cubatão, através da avaliação de seus condicionantes físicos e avaliar a contribuição das técnicas de Sistemas de Informação Geográfica na temática proposta.

Este trabalho se justifica pelo grande crescimento da indústria de dutos no Brasil e pela pressão natural provocada pelos últimos acidentes com vazamentos, que gerou um grande interesse por programas de integridade e confiabilidade.

Os diferentes graus de suscetibilidade obtidos pela carta gerada possibilitam a avaliação dos pontos mais suscetíveis ao processo de escorregamentos nos dutos já instalados da região e favorecem o planejamento de futuros traçados indicando, inclusive, trechos onde cuidados especiais devem ser tomados durante a instalação destes dutos.

\section{3 - ASPECTOS GERAIS DA ÁREA DE ESTUDO}

\section{1. - Localização da área}

A cidade de Cubatão localiza-se na Baixada Santista (litoral do Estado 
de São Paulo), a 57 km de distância da cidade de São Paulo, pela Rodovia Anchieta (Figura 1).

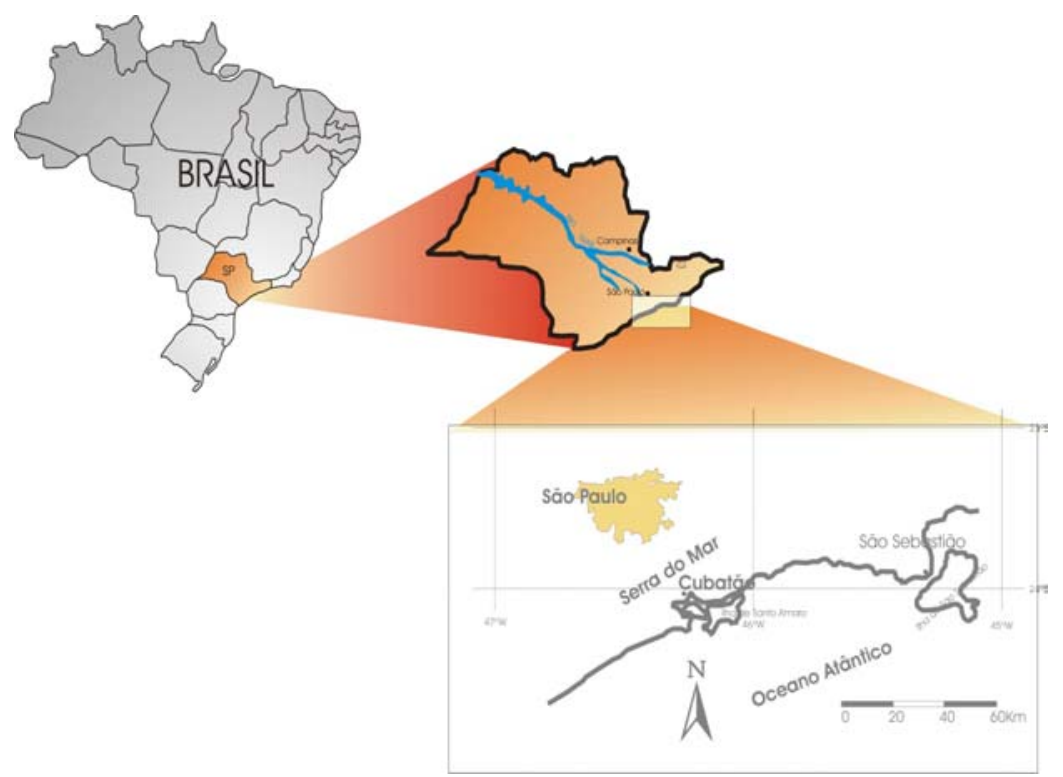

Figura 1: Localização da área de estudo

\section{2. - Geologia Regional}

Segundo Almeida (1984), a área de estudo está inserida no Escudo Cristalino Brasileiro, Pré-Cambriano Superior, em uma unidade denominada Complexo Costeiro, que se estende desde o estado do Rio de Janeiro até Santa Catarina. A zona de falhamentos de Cubatão divide a região em duas partes: Bloco Juquitiba ou Bloco Norte, e Bloco Litorâneo ou Bloco Sul.

As rochas do Bloco Litorâneo correspondem, quase que exclusivamente, a migmatitos oftalmíticos. Secundariamente, ocorrem migmatitos estromatíticos. Podem ocorrer cataclasitos e suítes graníticas. No Bloco Juquitiba ocorrem migmatitos estromatíticos e secundariamente, migmatitos oftalmíticos. Ocorrem ainda ectinitos, micaxistos, clorita xistos e filitos. Eventualmente há ocorrência de calcário, dolomito e metamarga. Localmente ocorrem intrusões ígneas básicas e ácidas (SADOWSKI, 1974).

\section{3. - Clima}

A Baixada Santista é considerada a área mais chuvosa do Brasil, sofrendo influência direta dos fatores geográficos locais. A Serra do Mar funciona como uma barreira para os ventos que sopram do mar para o continente, impedindo a dispersão dos poluentes presentes no ar, gerando altos índices de poluição, inclusive chuva ácida (MOREIRANORDEMANN et al., 1986). Devido a essa barreira, que gera maior 
pluviosidade, originou-se a Floresta Pluvial Tropical, um agente estabilizador dos perfis das encostas, que pode evitar os escorregamentos (VALERIANO; PONZONI, 1989).

Durante o verão, as frentes frias que se originam na região antártica cruzam o Oceano Atlântico sul e se deparam com as massas tropicais de ar quente. Esse encontro gera uma instabilidade atmosférica que, associada ao relevo escarpado, tem como conseqüência chuvas torrenciais (GUIDICINI; IWASA, 1976).

A precipitação anual da região de Cubatão chega a ultrapassar $3300 \mathrm{~mm}$ e estudos realizados pelo IPT (1985) mostram que as zonas mais chuvosas estão localizadas na borda da escarpa da Serra do Mar, com pluviosidade que pode chegar até $4000 \mathrm{~mm}$.

\section{4 - Vegetação}

A vegetação nativa é constituída por uma floresta densa, hoje restrita a locais onde não ocorrem atividades antrópicas. A vegetação secundária já se encontra degradada, devido à ação antrópica e à ação crônica dos poluentes atmosféricos oriundos de intensa atividade industrial (RODRIGUES, 1992). Houve um considerável aumento em número e em intensidade dos escorregamentos nas áreas de vegetação degradada (MENDONÇA e PAULICS, 1996).

A vegetação é importante na proteção do solo contra a ação das chuvas, porque diminui o escoamento superficial, reduzindo a infiltração da água. Dessa maneira, a alteração da rocha é retardada, diminuindo a suscetibilidade a processos erosivos e escorregamentos (CETESB, 1991).

\section{4 - Os SISTEMAS DE INFORMAÇÃO GEOGRÁFICA E O MODELO IMPLEMENTADO}

Segundo Bonham-Carter (1994), SIGs são sistemas de computador para o gerenciamento de dados espaciais, georreferenciados, interrelacionados e ligados a diferentes funções, exercendo tarefas de entrada, manipulação, visualização, análises, modelagem e saída; ao lado do Processamento Digital de Imagens (PDI).

O propósito dos Sistemas de Informação Geográfica (SIGs) é fornecer suporte em decisões a serem tomadas com base em dados espaciais, proporcionando uma seleção de prioridades, constituindo este processo, um modelo. Um modelo de dados fornece ferramentas para a organização lógica de bancos de dados e possibilita a manipulação de tais dados, de acordo com o enfoque da pesquisa a ser realizada. Existem diversos modelos implementados dentro de SIG, sendo que o utilizado neste projeto é denominado Processo Analítico Hierárquico (AHP - Analytical 
Hierarchy Process) (BONHAM-CARTER, 1994). A AHP funciona como uma ferramenta de suporte à decisão, que consiste na escolha entre alternativas mais ou menos importantes na ocorrência de qualquer processo e é baseada na interseção de mapas temáticos, que constituem os critérios, de mesma escala. Os critérios recebem um peso de acordo com sua importância no processo estudado e podem ter seu peso aumentado ou diminuído quando necessário. A partir do estabelecimento de critérios de comparação para cada combinação de fatores, é possível determinar um conjunto de pesos que podem ser utilizados para a geração de diferentes mapas. Existe um grande número de aplicações para a AHP, como zoneamento, prospecção mineral, seleção de áreas para disposição de resíduos, estudos de preservação ambiental em áreas de encosta para estabelecer uma política de ocupação, ou elaborar mapas de risco de movimentos de massa ou impacto ambiental (CÂMARA et al., 1996).

Os dados utilizados na análise são processados por combinação numérica, através de média ponderada, conforme segue:

\section{$\mathbf{S}=\boldsymbol{\Sigma} . \mathbf{S i j}$. Wi $/ \boldsymbol{\Sigma}$. Wi}

Onde: $\mathbf{S}=$ valor do peso para uma determinada área

$\mathbf{W i}=$ peso atribuído ao mapa temático

$\mathbf{S i j}=$ peso atribuído para cada classe do mapa temático

O Processo Analítico Hierárquico, por atribuir a devida importância a cada condicionante através da atribuição de pesos, propicia uma análise mais completa e se constitui em uma das formas de abordagem mais utilizadas dentro de Sistemas de Informação Geográfica (ARAUJO, 1999).

\section{5 - MOVIMENTOS GRAVITACIONAIS DE MASSA}

Os movimentos gravitacionais de massa são processos estudados em todo o mundo, constituindo um antigo problema da humanidade. São em grande parte responsáveis pela evolução das formas do relevo e causam grandes danos sócio-econômicos (GUIDICINI; NIEBLE, 1984). Podem ser classificados de acordo com o material envolvido, com o tipo de mecânica e a velocidade de movimentação (AUGUSTO FILHO e CERRI, 1988).

As escarpas da Serra do Mar ocupam a área da floresta tropical úmida, caracterizada por elevadas temperaturas e por chuvas torrenciais em determinadas épocas do ano, causando um processo de alteração intenso e predominantemente químico. Estas características, associadas ao relevo da área e aos tipos de rochas, podem desencadear processos de movimentos de massa, e são denominadas condicionantes ou variáveis dos movimentos de massa (IPT, 1985).

Apesar das condições favoráveis à formação de espessos mantos de alteração, devido ao intemperismo, há uma constante remoção dos detritos 
formados, devido à alta declividade das encostas. A remoção dos detritos formados dá-se basicamente pelos seguintes tipos de movimentos de massa: rastejos, escorregamentos translacionais e quedas de blocos. Na área de estudo, embora ocorram os outros processos, o tipo mais atuante na dinâmica superficial é o escorregamento translacional (AUGUSTO FILHO e CERRI, 1988).

O escorregamento também pode ser induzido pela ação antrópica, devido à ocupação inadequada da encosta, ou a cortes e aterros mal dimensionados, ou ao desmatamento e à conseqüente concentração de água nas encostas.

\section{6 - MÉTODOS UTILIZADOS}

\subsection{Levantamento dos condicionantes}

Foram levantadas as variáveis ou condicionantes dos escorregamentos translacionais, em função de sua importância como fator predisponente para a detonação do processo: geologia, declividade, geomorfologia e vegetação. A pluviosidade não foi considerada como condicionante, mas sim como principal agente deflagrador do processo, segundo considerações de Augusto Filho e Cerri, (1988). A etapa que se seguiu teve como objetivo transformar os condicionantes selecionados em mapas temáticos, para integrarem o modelo.

\section{2. - Elaboração do mapa base e dos mapas temáticos}

O mapa base foi gerado a partir da digitalização manual do mapa topográfico do IBGE, escala 1:50000, através do software AUTOCAD 2000 , de forma a conter informações de drenagem, principais estradas e curvas de nível, com seus respectivos valores de elevação.

O mapa de declividade foi produzido a partir do modelo numérico do terreno, obtido pela interpolação dos pontos cotados, existentes ao longo das curvas de nível do mapa base topográfico, através do modelo TIN (triangular irregular network).Este modelo se constitui num eficiente método de interpolação para a realização de modelos numéricos do terreno, pelo fato das faces do triângulo serem mais facilmente ajustadas às várias superfícies do relevo.

O modelo numérico obtido após a triangulação foi reclassificado, de forma a gerar quatro classes de declividade, segundo intervalos utilizados por IPT (1985): $\mathrm{A}<20^{\circ} ; 20^{\circ}<\mathrm{B}<30^{\circ} ; 30^{\circ}<\mathrm{C}<40^{\circ} ; \mathrm{D}>40^{\circ}$ (Figura 2). 


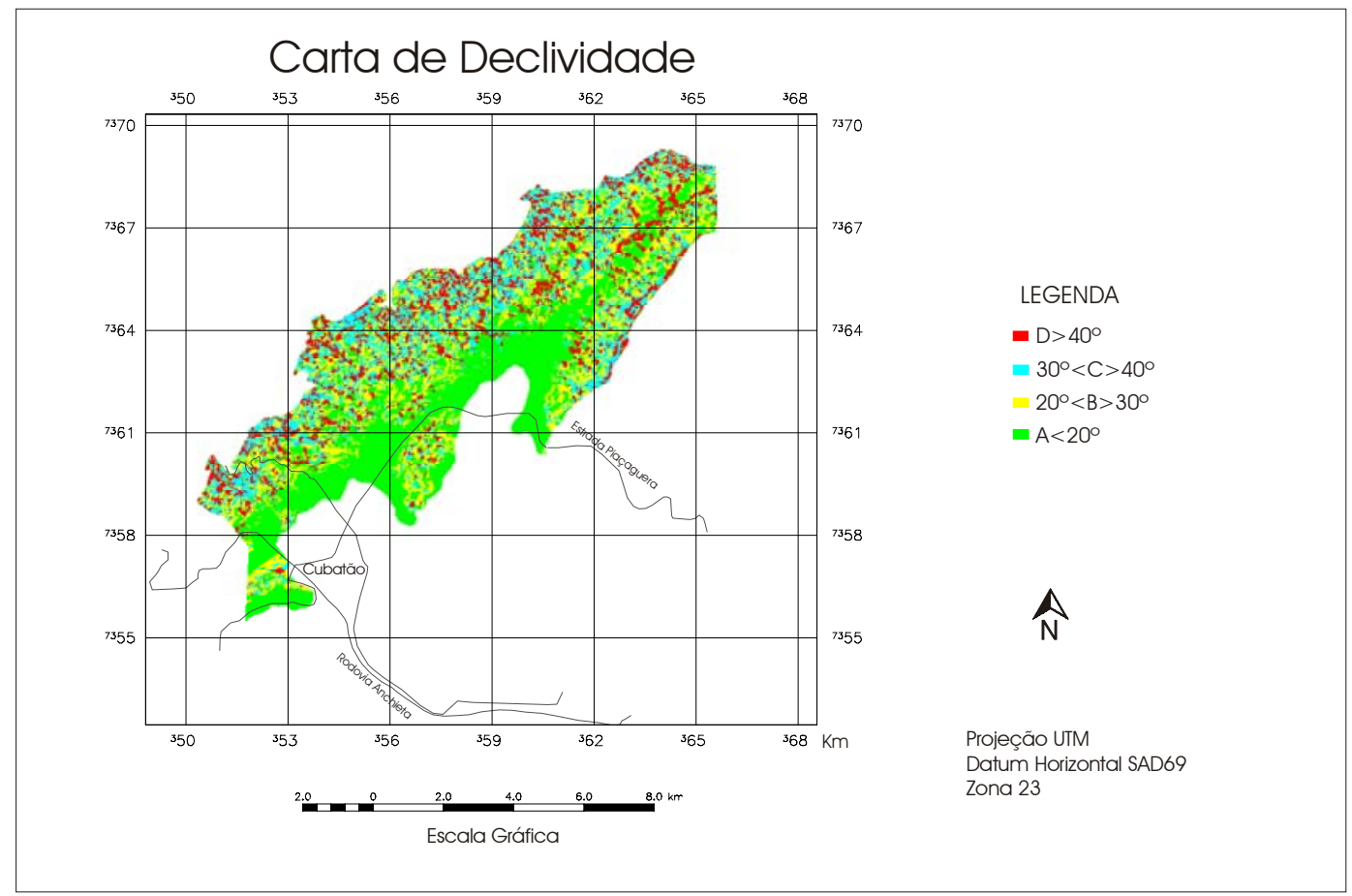

Figura 2 - Carta de declividade da região de Cubatão (SP), obtida a partir da carta topográfica do IBGE, escala 1:50000.

O mapa de cicatrizes de escorregamentos translacionais foi obtido a partir de registros de escorregamentos da Defesa Civil e foi digitalizado manualmente, com a utilização do software SPRING 4.0 (INPE, 2004).

O mapa de traçado dos dutos foi obtido através da interpretação de imagens do LANDSAT $7 \mathrm{ETM}+$, já georreferenciada, onde foram executados processamentos como ampliação linear de contraste e análise de componentes principais, para facilitar o reconhecimento de seus traçados e complementar informações existentes sobre suas localizações. Os polidutos, em sua maioria, seguem as principais estradas, tornando fácil a sua identificação ao longo destas. Os outros mapas temáticos, utilizados na modelagem, são citados a seguir.

Os mapas geológico (Figura 3), geomorfológico (Figura 4) e de vegetação (Figura 5), em escala 1: 50000 , foram obtidos de IPT( 1985) e foram digitalizados automaticamente por um scanner, com resolução de 300 dpi. Os mapas passaram então para o formato matricial, onde foram georreferenciados. A resolução calculada para os mapas temáticos, em função da escala de trabalho, de 1:100. 000, e da resolução utilizada no processo de digitalização automática, foi de $4,23 \mathrm{~m}$.

Em seguida, os mapas foram digitalizados em tela, através do software SPRING 4.0 (INPE, 2004) e, em seguida, foi criada a topologia, indispensável para qualquer análise espacial em SIG. 


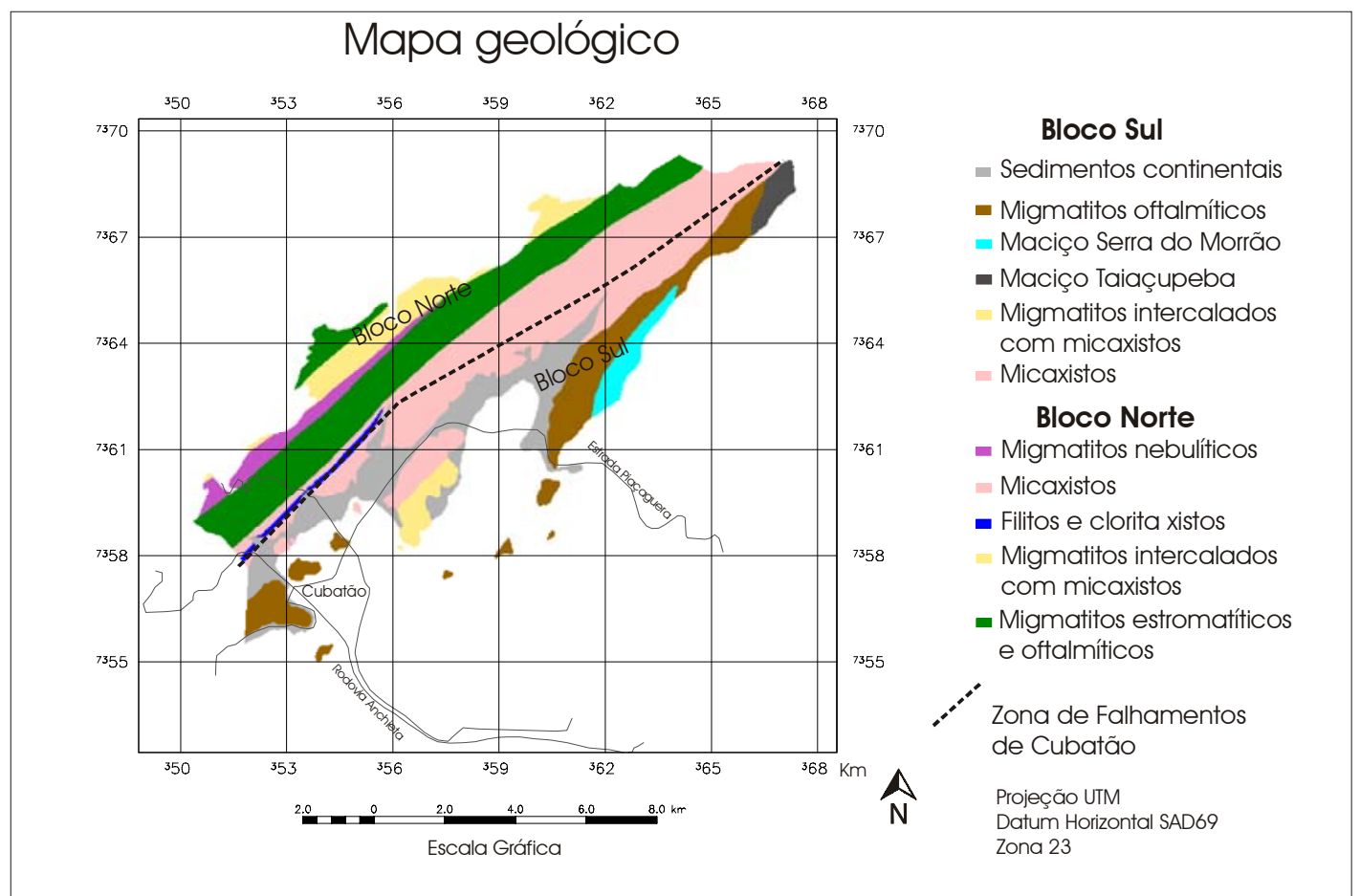

Figura 3 - Mapa geológico da região de Cubatão (SP). Fonte: IPT (1985)

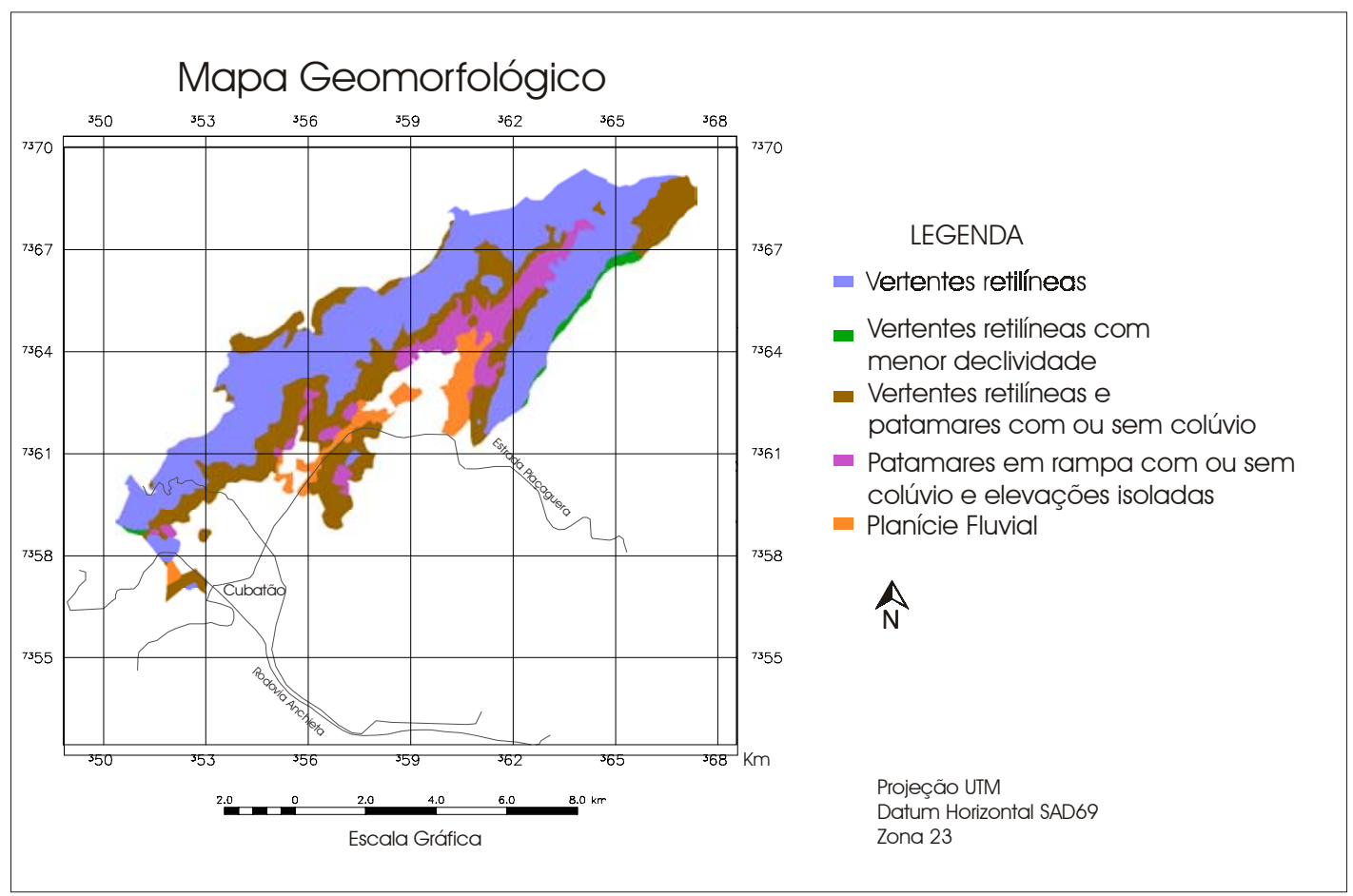

Figura 4 - Mapa Geomorfológico da região de Cubatão (SP). Fonte: IPT (1985) 


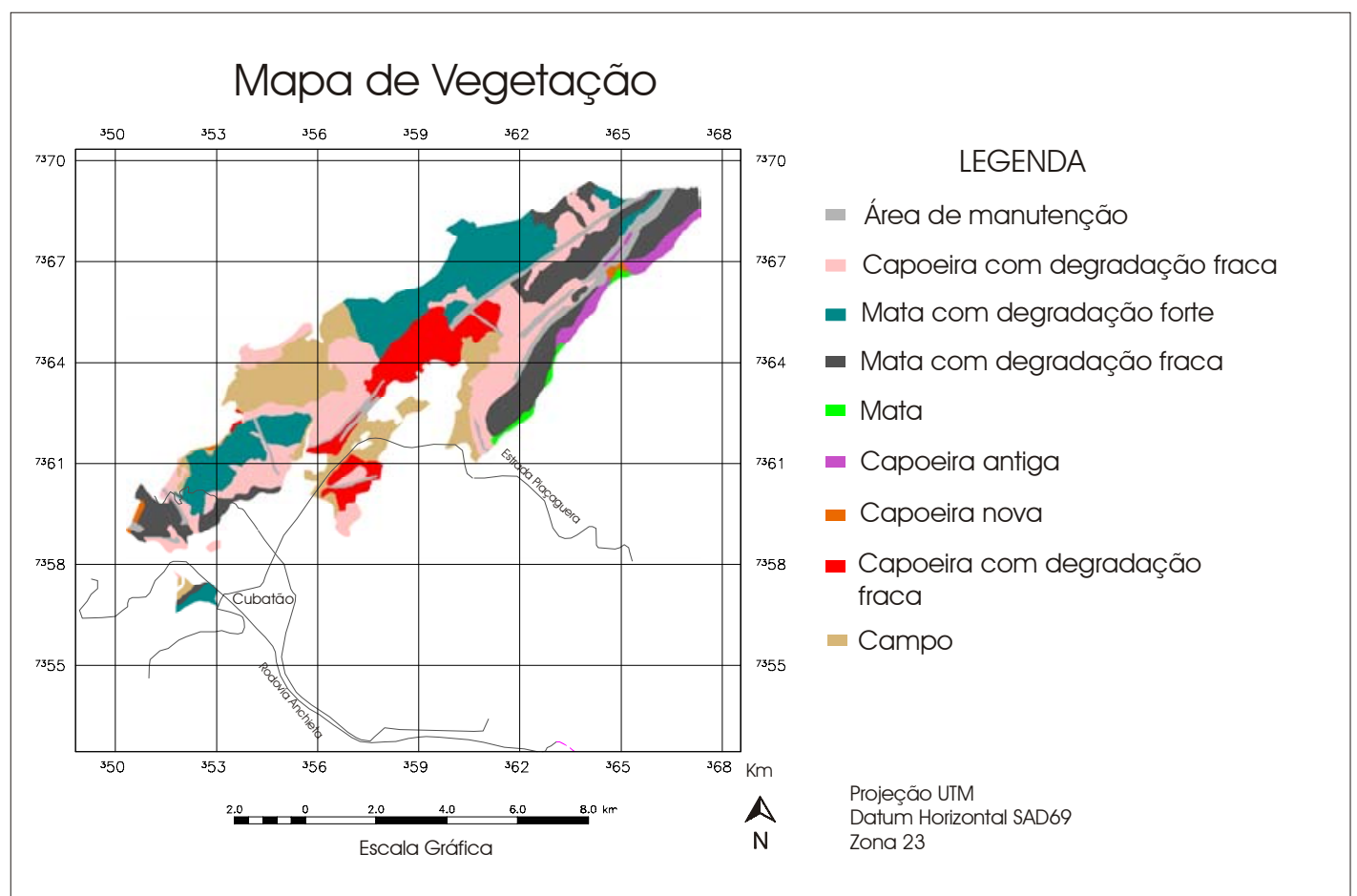

Figura 5 - Mapa de vegetação da região de Cubatão (SP). Fonte: IPT (1985)

\section{3. - Tratamento e integração dos dados}

Os mapas temáticos gerados foram submetidos ao Processo Analítico Hierárquico (AHP), citado anteriormente, no qual são atribuídos pesos aos mapas, que representam os condicionantes do processo, e também às classes dos mapas, constituindo-se numa soma ponderada, para gerar uma carta de suscetibilidade aos escorregamentos translacionais em Cubatão (SP).

\subsection{1 - Pesos dos mapas temáticos}

Para gerar a carta de suscetibilidade aos escorregamentos translacionais através do Processo Analítico Hierárquico, os vários condicionantes, representados através dos mapas temáticos, foram analisados quanto à sua importância relativa na deflagração do processo e, segundo essa importância, foram calculados os pesos numéricos de cada um deles no processo sob análise.

A atribuição de pesos pode ser feita estatisticamente, o que acontece nos modelos "data driven", para a geração de mapas probabilísticos, ou baseada no conhecimento dos profissionais sobre o assunto, como no modelo do tipo "knowlegde driven", utilizado neste trabalho. Estes profissionais analisam a importância relativa entre os vários condicionantes, o que deve ser feito também com o apoio de dados publicados e, muitas vezes, com apoio de consultores $A D H O C$, que podem opinar sobre o assunto. 
No caso do presente trabalho, baseado nos julgamento dos autores e com respaldo de dados existentes sobre os escorregamentos translacionais estudados na região da Serra do Mar paulista e, especificamente, na região de Cubatão, os condicionantes com maior importância relativa no processo, e importâncias iguais, foram a geomorfologia e a declividade, já que a ocorrência de um escorregamento translacional está intimamente ligada a altas declividades e vertentes retilíneas. A vegetação foi avaliada como tendo a segunda maior importância, já que a ausência da cobertura vegetal potencializa o processo, constituindo, portanto, num importante fator para a suscetibilidade. O condicionante geologia foi considerado como tendo a menor importância relativa no processo. Existem tipos de rochas mais favoráveis ao escorregamento, como as que apresentam planos de fraqueza, xistosidade, fraturas ou alterações, porém, estas devem estar associadas a altas declividades e vertentes retilíneas ou côncavas para que o processo seja deflagrado. Com base nas importâncias relativas, consideradas dois a dois, são calculados pelo software os pesos correspondentes a cada condicionante.

Nesta etapa, a soma dos pesos calculados deve ser igual a 1 (um) e é aconselhável que a Razão de Consistência obtida seja sempre menor que 0,1. Esta razão mede a coerência e a consistência das relações de importância consideradas na análise. Caso a razão de consistência obtida seja superior a 0,1 , o julgamento dos condicionantes deve ser refeito, por apresentar incoerências. Quanto mais próxima de "0" for a razão de consistência, mais coerente será o modelo. O cálculo de pesos deste trabalho, expostos na Tabela 1, resultou em uma Razão de Consistência igual a 0,008 , o que caracteriza um modelo coerente.

Tabela 1: Pesos atribuídos aos condicionantes abordados.

\begin{tabular}{|c|c|}
\hline Condicionantes & Peso calculado \\
\hline Geologia & 0,082 \\
\hline Declividade & 0,359 \\
\hline Geomorfologia & 0,359 \\
\hline Vegetação & 0,200 \\
\hline
\end{tabular}

\subsection{2. - Pesos das classes dos mapas temáticos}

Os pesos atribuídos às classes dos mapas temáticos foram fundamentados no conhecimento do processo, apoiado pela pesquisa bibliográfica realizada, também caracterizando o modelo "knowlegde driven" utilizado.Nesta etapa, porém, conforme os procedimentos exigidos pelo software SPRING (INPE, 2004) utilizado, são atribuídos diretamente os valores numéricos, correspondentes aos pesos, de acordo com a 
influência de cada classe temática na deflagração do processo, no caso, os escorregamentos translacionais. Estes pesos podem variar de acordo com o processo a ser analisado, com a área de estudo e sua dinâmica superficial e até mesmo com o julgamento de cada pesquisador, podendo ser modificados a qualquer momento.

Os pesos foram atribuídos dentro de um intervalo de 0 a 1 , onde os menores valores representam as classes com menor importância relativa no processo, enquanto os maiores valores estão relacionados às classes que têm maior influência na deflagração dos escorregamentos, conforme tabelas a seguir:

Tabela 2: Pesos atribuídos às classes temáticas de geologia.

\begin{tabular}{|l|c|}
\hline \multicolumn{1}{|c|}{ Classes temáticas de geologia } & Pesos atribuídos \\
\hline Maciços graníticos & 0,1 \\
\hline $\begin{array}{l}\text { Migmatitos oftalmíticos, nebulíticos, com paleossomas } \\
\text { graníticos e gnáissicos }\end{array}$ & 0,4 \\
\hline Migmatitos com paleossoma de micaxistos & 0,6 \\
\hline Micaxistos & 0,8 \\
\hline Filitos e clorita xistos & 0,8 \\
\hline
\end{tabular}

Tabela 3: Pesos atribuídos às classes temáticas de declividade.

\begin{tabular}{|c|c|}
\hline Classes temáticas de declividade & Pesos atribuídos \\
\hline $\mathbf{A}<20^{\circ}$ & 0,2 \\
\hline $20^{\circ}<\mathbf{B}<30^{\circ}$ & 0,4 \\
\hline $30^{\circ}<\mathbf{C}<40^{\circ}$ & 0,8 \\
\hline $\mathbf{D}>40^{\circ}$ & 0,8 \\
\hline
\end{tabular}

Tabela 4: Pesos atribuídos às classes temáticas de vegetação.

\begin{tabular}{|l|c|}
\hline \multicolumn{1}{|c|}{ Classes temáticas de vegetação } & Pesos atribuídos \\
\hline Mata (cobertura florestal) & 0,1 \\
\hline Capoeira antiga & 0,1 \\
\hline Capoeira nova & 0,1 \\
\hline Mata com degradação fraca & 0,3 \\
\hline Campo & 0,3 \\
\hline Mata com degradação forte & 0,5 \\
\hline Capoeira com degradação fraca & 0,5 \\
\hline Capoeira com degradação forte & 0,8 \\
\hline Área de manutenção (linhas de transmissão ou & 0,8 \\
\hline vias de transporte) & \\
\hline
\end{tabular}


Tabela 5: Pesos atribuídos às classes temáticas de geomorfologia.

\begin{tabular}{|l|c|}
\hline \multicolumn{1}{|c|}{ Classes temáticas de geomorfologia } & Pesos atribuídos \\
\hline Planície fluvial & 0,0 \\
\hline Patamares com ou sem colúvio, e elevações isoladas & 0,2 \\
\hline Vertentes retilíneas e patamares com ou sem colúvio & 0,3 \\
\hline Vertentes retilíneas & 0,8 \\
\hline
\end{tabular}

Segundo Augusto Filho et al (1988), as classes geomorfológicas podem ser associadas às espessuras de solo. As encostas retilíneas são associadas à menor profundidade de solo, aqui considerada rasa, enquanto que as encostas côncavas são associadas a solos de espessura mediana. Já as encostas convexas, por sua vez, são ligadas a solos de maior espessura, aqui considerados profundos. Esta associação complementou a análise, visto que as encostas retilíneas, que dominam a área, possuem menor espessura de solo, o que é característico de áreas onde se desenvolvem os escorregamentos translacionais.

O mapa de suscetibilidade gerado apresenta valores de 0 a 1 , o mesmo intervalo dos pesos utilizados na modelagem,. Este mapa foi então reclassificado, de forma a gerar três classes, de acordo com os seguintes intervalos: a) baixa suscetibilidade - intervalo entre $0-0,4$; b) média suscetibilidade - intervalo entre $0,4-0,65$; c)alta suscetibilidade - intervalo entre $0,65-1$, segundo apresentado na Figura 6.

Os pesos atribuídos aos condicionantes e às classes dos condicionantes podem ser alterados em qualquer momento do estudo, dependendo da análise que se quer fazer. Após qualquer alteração nos pesos, o processo da AHP deve ser executado novamente, para que o mapa final seja atualizado a cada nova modificação.

A carta obtida foi confrontada com as ocorrências de cicatrizes de escorregamentos já cadastradas, pela Defesa Civil, para validação do processo, e com o traçado dos polidutos, para avaliação de suas posições em relação às áreas de suscetibilidade.

\section{7 - DISCUSSÃO DOS RESULTADOS}

A carta de suscetibilidade aos escorregamentos translacionais, na escala 1:100.000, evidencia áreas com três diferentes classes de suscetibilidade, sintetizadas na Tabela 6 e na Figura 6: 
Tabela 6: Apresentação dos resultados.

\begin{tabular}{|c|c|c|c|c|c|}
\hline $\begin{array}{c}\text { Classes de } \\
\text { suscetibilidade }\end{array}$ & Litotipos & Vegetação & Declividade & Geomorfologia & $\begin{array}{l}\text { Área } \\
(\%)\end{array}$ \\
\hline Alta & \begin{tabular}{|l|} 
Filitos \\
Micaxistos \\
Migmatitos \\
intercalados \\
com micaxistos \\
\end{tabular} & $\begin{array}{l}\text { Vegetação com } \\
\text { forte degradação, } \\
\text { área de } \\
\text { manutenção, } \\
\text { campo }\end{array}$ & $\begin{array}{l}>30^{\circ} \text { (classes } \\
\text { C e D) }\end{array}$ & $\begin{array}{l}\text { Vertentes } \\
\text { retilíneas, áreas } \\
\text { de cabeceira de } \\
\text { drenagem }\end{array}$ & $46 \%$ \\
\hline Média & $\begin{array}{l}\text { Migmatitos } \\
\text { intercalados por } \\
\text { quartzitos }\end{array}$ & $\begin{array}{l}\text { Vegetação com } \\
\text { baixa degradação }\end{array}$ & $20^{\circ}<\mathrm{B}<30^{\circ}$ & $\begin{array}{ll}\text { Vertentes } & \\
\text { retilíneas } & \mathrm{e} \\
\text { patamares } & \text { em } \\
\text { rampa com } & \text { ou } \\
\text { sem colúvio } & \end{array}$ & $44 \%$ \\
\hline Baixa ou nula & $\begin{array}{l}\text { Migmatitos } \\
\text { granitóides }\end{array}$ & $\begin{array}{lr}\text { Área } & \text { agrícola, } \\
\text { capoeira } & \text { de } \\
\text { planície, } & \text { capoeira } \\
\text { antiga, } & \text { capoeira } \\
\text { nova } & \end{array}$ & $\mathrm{A}<20^{\circ}$ & $\begin{array}{l}\text { Planície fluvial, } \\
\text { elevações isoladas }\end{array}$ & $10 \%$ \\
\hline
\end{tabular}

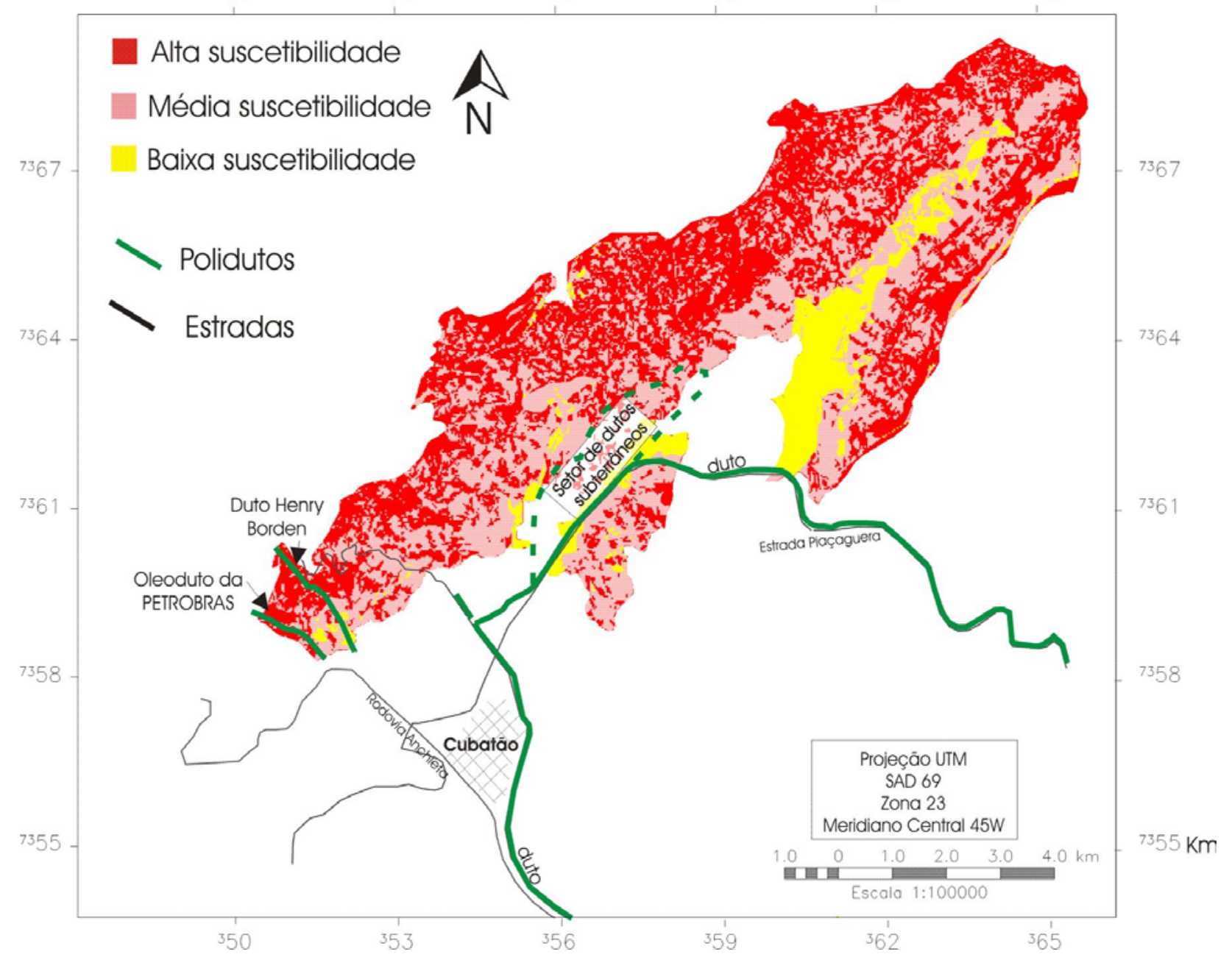

Figura 6: Carta de suscetibilidade aos escorregamentos translacionais. 
- Suscetibilidade alta - Áreas onde estão presentes os condicionantes mais propícios a escorregamentos. A ocorrência de escorregamentos translacionais é iminente, podendo ser desencadeada ou acelerada pela pluviosidade, e se apresentam generalizadas por toda a região.

- Suscetibilidade média - Áreas que não reúnem todos os condicionantes propícios a escorregamentos, e possuem poucas cicatrizes mapeadas. Também se apresentam de forma generalizada na região.

- Suscetibilidade baixa - Áreas que reúnem condicionantes pouco propícios à ocorrência de escorregamentos translacionais. Não se espera que ocorram escorregamentos nas regiões de baixa suscetibilidade.

A carta foi analisada em conjunto com o traçado dos polidutos, para a avaliação do seu posicionamento em relação às áreas de diferentes suscetibilidades a escorregamentos translacionais. Pode-se concluir que o oleoduto da PETROBRAS se encontra quase que inteiramente em área de alta suscetibilidade. Este possui trajeto subterrâneo por toda a Baixada, exceto na subida à encosta da Serra do Mar, na porção oeste da área de estudo. O mesmo pode ser dito para o duto da Usina Henry Borden, próximo ao oleoduto da PETROBRAS, na porção oeste. Os outros dutos, não especificados pela bibliografia consultada, têm seu trajeto ao longo das principais rodovias, locais caracterizados por Augusto Filho et al. (1988) como áreas de manutenção, atribuídas a áreas de alta suscetibilidade devido à ausência da vegetação como protetora do solo ou rocha. $\mathrm{O}$ duto que tem seu trajeto ao longo da Rodovia Piaçaguera está quase que inteiramente em área de baixa suscetibilidade, já que se situa em uma planície fluvial.

Foi mapeado por IPT (1985) um setor no qual estão instalados dutos subterrâneos, o qual se encontra parte em área urbanizada e parte em área predominantemente de média suscetibilidade.

\section{8- CONCLUSÕES E RECOMENDAÇÕES}

Com base nos dados obtidos e nos métodos utilizados, foi elaborada uma Carta de Suscetibilidade aos Escorregamentos Translacionais, na qual foram definidas três classes de suscetibilidade: alta, média e baixa. A área de estudo apresenta altas declividades, grande parte da vegetação já degradada e predominância de vertentes retilíneas, altos índices pluviométricos e já foi cenário de escorregamentos catastróficos. De acordo com os resultados obtidos, a área de estudo pode ser considerada como um meio altamente suscetível a escorregamentos translacionais.

As áreas de alta suscetibilidade se localizam em todas as porções mais elevadas das escarpas da Serra do Mar, onde as vertentes são retilíneas. Já as áreas de média suscetibilidade se encontram nas meias encostas. Áreas 
com baixa suscetibilidade se localizam na porção leste da área estudada, onde predominam planícies fluviais, e áreas de declividade muito baixa.

Pode-se concluir que a utilização dos Sistemas de Informações Geográfica fornece subsídios para a tomada de decisão em relação à malha dutoviária de Cubatão, uma vez que possibilita uma análise com os condicionantes do meio físico que contribuem para a ocorrência dos escorregamentos translacionais, permitindo ainda a manipulação dos pesos e a inserção de mais variáveis ao modelo, de acordo com a necessidade do estudo.

O uso de recursos de SIG torna as análises bem mais flexíveis e rápidas que os tradicionais métodos de sobreposição física de mapas temáticos. O Processo Analítico Hierárquico constituiu uma eficiente ferramenta para a geração da Carta de Suscetibilidade a Escorregamentos, visto que considera de forma ponderada todos os condicionantes do meio físico, dependendo do objetivo do trabalho.

A carta de suscetibilidade gerada neste projeto permite a visualização dos pontos críticos em relação aos escorregamentos translacionais ao longo dos dutos, subsidiando um melhor planejamento das atividades ao redor deles. Esta avaliação também possibilita a previsão de um trajeto adequado à malha dutoviária a ser planejada, em relação ao meio físico e aos problemas que podem vir a ocorrer.

É recomendado que este tipo de trabalho seja executado antes da instalação de uma malha dutoviária ou de qualquer obra que configure uma alteração no meio físico. Também é sugerido que, uma vez havendo a necessidade dos dutos serem instalados numa área de alta suscetibilidade, medidas mitigadoras e recuperadoras sejam cuidadosamente observadas durante as etapas de elaboração do projeto executivo, implantação e operação da obra.

\section{9- AGRADECIMENTOS}

As autoras agradecem à Agência Nacional de Petróleo (ANP), através de seu Programa de Recursos Humanos (PRH 05), pelo apoio concedido.

\section{0 - REFERÊNCIAS}

ALMEIDA, F.F.F. Fundamentos geológicos do relevo paulista - In: Geologia do Estado de São Paulo, São Paulo: IG/USP, p.56-62., 1984. ARAÚJO, P.C. Aplicação de Sistema de Informação Geográfica na escolha de áreas para disposição de resíduos sólidos no município de Americana (SP). 91p., 1999. (Mestrado em Geociências e Meio 
Ambiente) - Instituto de Geociências e Ciências Exatas, Universidade Estadual Paulista, Rio Claro.

AUGUSTO FILHO, O.; CERRI, L.E.S. Programa Serra do Mar: Carta geotécnica da Serra do Mar nas folhas de Santos e Riacho Grande. São Paulo: Instituto de Pesquisas Tecnológicas. 49p.,1988.

BONHAM-CARTER, G.F. Geographic Information Systems for geoscientists: Modelling with GIS. Otawa: Pergamon, 398p., 1994.

CÂMARA, G.;SOUZA, R.C.M.; FREITAS,U.M.;GARRIDO, J. SPRING: Integrating remote sensing and GIS by object-oriented data modelling. Computers and Graphics, v.20, n.3, 395-403, 1996.

COMPANHIA DE TECNOLOGIA DE SANEAMENTO AMBIENTAL "(CETESB)". Carta morfodinâmica da Serra do Mar na região de Cubatão - São Paulo. São Paulo, 1991. 36p. Relatório.

GUIDICINI, G.; IWASA, O.Y. Ensaio de correlação entre pluviosidade e escorregamentos em meio tropical úmido. São Paulo. IPT, 1976.

GUIDICINI, G.; NIEBLE, C. M. Estabilidade de taludes naturais e de Escavação. $2^{\circ}$ Edição. São Paulo. Edgard Blücher, 1984, 194p.

INSTITUTO DE PESQUISAS TECNOLÓGICAS DO ESTADO DE SÃO PAULO- IPT. Elaboração de subsídios técnicos para um plano de emergência para a área de Cubatão, Estado de São Paulo. São Paulo. 1985 (IPT, Relatório n ${ }^{\circ} 22.797$ ).

INSTITUTO NACIONAL DE PESQUISAS ESPACIAIS -INPE. SPRING. São José dos Campos, 2004. CD ROM.

MENDONÇA, R.R.; PAULICS, J.P.J. Monitoramento do desenvolvimento das espécies vegetais da Mata Atlântica introduzidas em três bosques experimentais no Vale do Moji, Caminho do Mar e Vale dos Pilões. São Paulo: (CETESB), 1996. 99p. Relatório.

MOREIRA-NORDEMANN, L.M., DANELON, O.M.; FORTI, M.C.; ESPÍRITO SANTO, C.M.; SARDELA, D.D.; LOPES, J.C.; FILHO, B.M.; ABBAS, M.M.. Caracterização química das águas de chuva de Cubatão. São José dos Campos: INPE, 63 p., 1986. (3965-RPE/515).

RODRIGUES, R. Características geológicas e geotécnicas intervenientes na estabilidade de massas coluviais da Serra do Cubatão - SP. 116p., 1992. (Mestrado) - Escola de Engenharia de São Carlos, Universidade de São Paulo, São Carlos.

SADOWSKI, G. R. Tectônica da Serra de Cubatão, S.P. 160p., 1974. (Tese de Doutorado em Geociências) - Instituto de Geociências, Universidade de São Paulo, São Paulo.

VALERIANO, D.M.; PONZONI, F.J. A fotointerpretação como instrumento para avaliação de impacto ambiental: a Mata Atlântica em Cubatão. São José dos Campos: INPE, 18p., 1989. (4910-PRE/1511). 